\title{
Rectal hyperplasia after jejunoileal bypass for morbid obesity
}

\author{
G $V$ N APPLETON, E E WHEELER, R AL-MUfTi, D N CHALLACOMBE, \\ AND R C N WILLIAMSON
}

From the University Department of Surgery, Bristol Royal Infirmary and Somerset Children's Research Unit, Musgrove Park Hospital, Taunton, Somerset

SUMmaRY Jejunoileal bypass (JIB) has been widely used to treat patients with morbid obesity for the past 20 years. In rats JIB causes adaptive colonic hyperplasia and enhances colorectal neoplasia. In this study crypt cell production rate (CCPR) was measured stathmokinetically in cultured rectal biopsies from nine patients with JIB and seven controls without intestinal operations or disease. Crypt cell production rate in the group with JIB was more than double that of controls $(12 \cdot 80(2 \cdot 67) v$ $6 \cdot 23(1 \cdot 49)$ cells/crypt/h: $p<0 \cdot 001)$. There were no significant differences in crypt morphometry and histological examination of rectal biopsies was normal. Patients with JIB have a marked and persistent increase in cell proliferation in the large intestine and may be at increased risk of developing colonic cancer.

During the 20 years since jejunoileal bypass (JIB) was introduced for the treatment of morbid obesity, ${ }^{1}$ it is estimated that over 100000 such operations have been carried out in the USA alone. ${ }^{2}$ In rats, end-toside JIB stimulates adaptive growth and enhances chemical carcinogenesis in the colon, ${ }^{3}$ although extreme weight loss can limit these effects. ${ }^{4}$ Similar phenomena in man would place a large group of young patients at increased risk of developing colorectal carcinoma, even if insufficient time has yet elapsed to reveal the threat. The operation probably reached its peak of popularity in the late 1970s. To date at least two patients have been reported with subsequent colorectal neoplasia: one developed a carcinoma $^{5}$ and the other two tubulovillous adenomas. ${ }^{\circ}$

As experimental hyperplasia precedes and predisposes to neoplasia in the large intestine, ${ }^{7}$ we have looked for evidence of permanent adaptation in the rectum of patients with previous JIB. The technique has involved measuring crypt cell production in mucosal biopsies maintained in short term organ culture.

Address for correspondence: Dr D N Challacombe, Somerset Children's Research Unit, Musgrove Park Hospital, Taunton, Somerset TA1 5DA. Received for publication 13 May 1988.

\section{Methods}

PATIENTS AND BIOPSIES

Nine patients were studied from among those who had undergone JIB for morbid obesity in Bristol over the last 11 years. The standard operative procedure comprised end-to-side bypass between $35 \mathrm{~cm}$ proximal jejunum and $15 \mathrm{~cm}$ terminal ileum. Patients were reviewed with particular regard to weight change and current bowel habit. Seven controls who were attending outpatients for the treatment of haemorrhoids, and had no known colonic disease, were also studied. Patients gave informed consent, and approval was obtained from the appropriate health authority. A sigmoidoscopy was carried out and two biopsies were taken from the upper rectum (10-12 cm from the anal verge) using Patterson biopsy forceps (Down Bros). Samples were gently washed before being transported in ice cold Leibowitz L-15 medium (GIBCO).

ORGAN CULTURE

Using an aseptic technique previously described, ${ }^{8}$ biopsies were gently orientated and flattened with the mucosal surface uppermost on a Metricell filter. They were then divided into $2-3 \mathrm{~mm}^{2}$ explants and transferred onto stainless steel grid platforms placed at 
one end of the well of a Lux multiwell culture dish (Flow Labs). The culture medium contained CMRL1066 (GIBCO) $91.5 \% \mathrm{v} / \mathrm{v}$, fetal calf serum (GIBCO) $5 \%$, L-glutamine $(200 \mathrm{mM}) 2 \%$, Hepes buffer (1 M) $1 \%$, and penicillin+streptomycin $(10000 \mathrm{IU} / \mathrm{ml})$ $0 \cdot 5 \%$. Glucose $(20 \mathrm{mg})$, hydrocortisone 21 hemisuccinate $(1 \mathrm{mg})$, and insulin $(1 \mathrm{mg})$ were added to each $20 \mathrm{ml}$ of medium, which had a final $\mathrm{pH}$ of 7.27.3. Each well contained $3 \mathrm{ml}$ of medium and was rocked at 3 cycles $/ \mathrm{min}$ at $37^{\circ} \mathrm{C}$ in a Bellco controlled atmosphere chamber containing $95 \%$ oxygen and $5 \%$ carbon dioxide. Explants were established in organ culture within 60-75 minutes of obtaining the biopsy.

CRYPT CELL PRODUCTION RATE (CCPR)

A culture time of $15 \mathrm{~h}$ was selected on the basis of a small pilot experiment (see below). The stathmokinetic agent vincristine $0.6 \mu \mathrm{g} / \mathrm{ml}$ (Oncovin, Eli Lilly, Basingstoke) was added to each culture well to bring about metaphase arrest within the intestinal crypts. ${ }^{9}$ Explants were removed after one, two, and three hours of culture (between three to five explants/ time point). Samples were fixed in Carnoy's fluid for four hours and stored in $70 \%$ alcohol. Specimens were later stained by the Feulgen method for DNA, and individual crypts in each sample were separated by microdissection. ${ }^{10}$ The number of arrested metaphase figures was counted in 20 crypts/specimen, and the mean value was plotted against time after vincristine administration. The CCPR was calculated by linear regression analysis. ${ }^{9}$

In the pilot experiment rectal biopsies from two controls and one patient with JIB were cultured over 24 hours in order to determine the optimum length of culture before measuring CCPR. Vincristine $(0 \cdot 6 \mu \mathrm{g})$ $\mathrm{ml}$ ) was added to successive wells at three hour intervals from three to 21 hours of culture. Specimens were removed three hours after first exposure to vincristine, and the mean number of metaphase arrests/crypt at each sampling time was determined as previously described.

\section{CRYPT MORPHOMETRY}

In four controls and five patients with JIB a modular image analysing system (Kontron MOP/AMO2), consisting of a glass evaluating tablet and a stylus linked to a microcomputer, was used to measure the crypt width and crypt area in 30 crypts per specimen. ${ }^{1}$ Camera lucida drawings were made of the microdissected crypts using a Leitz Dialux 20EB light microscope with a drawing tube attachment, and measurements were made on the evaluating tablet.

HISTOLOGY

Five micron sections were cut from the biopsies before and after the period of organ culture. Slides
Table 1 Patients with jejunoileal bypass (JIB)

\begin{tabular}{|c|c|c|c|c|c|}
\hline $\begin{array}{l}\text { Age } \\
(y r)\end{array}$ & $\begin{array}{l}\text { Time since } \\
J I B(y r)\end{array}$ & $\begin{array}{l}\text { Wt pre- } \\
J I B(k g)\end{array}$ & $\begin{array}{l}\text { Wt post- } \\
\text { JIB }(\mathrm{kg})\end{array}$ & $\begin{array}{l}\text { Daily bowel } \\
\text { actions }(n)\end{array}$ & $\begin{array}{l}\text { Rectal CCPR } \\
(\text { mean }(S E))\end{array}$ \\
\hline 49 & 11 & 146 & 77 & 4 & $12 \cdot 0(1 \cdot 2)$ \\
\hline 46 & 1 & 146 & 77 & 8 & $16.7(2.4)$ \\
\hline 33 & $0 \cdot 5$ & 222 & 185 & 9 & $13 \cdot 1(2 \cdot 5)$ \\
\hline 50 & 7 & 141 & 93 & 4 & $12.7(0.4)$ \\
\hline 40 & 2 & 159 & 102 & 3 & $8 \cdot 2(1.0)$ \\
\hline 43 & 3 & 254 & 146 & 10 & $16 \cdot 7(2.9)$ \\
\hline 31 & 3 & 124 & 67 & 6 & $10 \cdot 8(1 \cdot 6)$ \\
\hline 44 & $0 \cdot 2$ & 149 & 117 & 7 & $13 \cdot 4(0 \cdot 1)$ \\
\hline 31 & 0.5 & 149 & 105 & 6 & $12 \cdot 1(1 \cdot 4)$ \\
\hline
\end{tabular}

$\mathrm{CCPR}=$ crypt cell production rate (cells/crypt/hour).

Table 2 Details of control patients

\begin{tabular}{lcl}
\hline Age $(y r)$ & $W t(k g)$ & Rectal CCPR (mean $(S E))$ \\
\hline 56 & 76 & $7 \cdot 4(1 \cdot 4)$ \\
17 & 140 & $4 \cdot 4(0 \cdot 6)$ \\
38 & 70 & $5 \cdot 7(0 \cdot 7)$ \\
22 & 57 & $5 \cdot 3(0 \cdot 6)$ \\
56 & 73 & $7 \cdot 1(0 \cdot 1)$ \\
40 & 64 & $5 \cdot 4(0 \cdot 6)$ \\
29 & 89 & $8 \cdot 6(0 \cdot 6)$ \\
\hline
\end{tabular}

$\mathrm{CCPR}=$ crypt cell production rate (cells/crypt/hour).

were stained with haematoxylin and eosin and were examined by routine light microscopy for evidence of inflammation or dysplasia.

STATISTICAL ANALYSIS

Student's $t$ test was used to compare body weight, morphometric indices, and CCPR regression lines.

\section{Results}

PATIENTS (Tables 1,2 )

Patients with jejunoileal bypass (median age 43 years; range 31-50) had undergone operations a median two years before biopsy (range two months11 years). All the patients had lost weight as a result of the operation from a preoperative value of 165 (43) $\mathrm{kg}$ (mean (SE)) to 107 (39) $\mathrm{kg}$, a mean decline of $35 \%$. Patients had between three to 10 loose bowel actions/day. Controls were of similar age (median 38 years, range $17-56$ ) but weighed $30 \%$ less at the time of biopsy (81 (28) kg, NS).

\section{PILOT EXPERIMENT (Fig. 1)}

After an initial 'shock' phase in culture lasting nine hours, the mean number of arrested metaphases/ crypt at each three hour period of culture rose to a maximum of 16.25 in controls and 48.5 in JIB when vincristine was added at 15 hours; values then declined to 21 hours. Thus 15 hours was selected as 
the optimum length of culture. Values in JIB patients exceeded those of controls at all time points.

CRYPT CELL PRODUCTION RATE (CCPR)

Both groups showed near linear rates for accumulation of arrested metaphases (Fig. 2). Among controls the mean CCPR was 6.23 (1.49) cells/crypt/h (SE). Among patients with JIB the value was $105 \%$ higher $(12.80(2.67): p<0.001)$. There was virtually no overlap between the groups (Fig. 3).

CRYPT MORPHOMETRY

After JIB crypts were $18 \%$ wider $(0 \cdot 141(0 \cdot 048) \mathrm{mm} v$ $0.127(0.036) \mathrm{mm})$ and their area was $29 \%$ greater $\left(0.079(0.031) \mathrm{mm}^{2} v 0.061(0.020) \mathrm{mm}^{2}\right)$. Neither of these differences reached statistical significance.

HISTOLOGY

Examination of histological sections obtained before culture showed no evidence of proctitis nor of dysplasia. After 18 hours culture there was good preservation of the normal mucosal architecture.

\section{Discussion}

We have used the technique of organ culture to study adaptation of the human large intestine. Patients who had undergone jejunoileal bypass for morbid obesity had crypt cell production rates that were more than twice as rapid as controls and these rates still remained raised up to 11 years postoperatively. As in the rat, therefore, adaptation of the shortened gut develops rapidly, and persists indefinitely in man.?

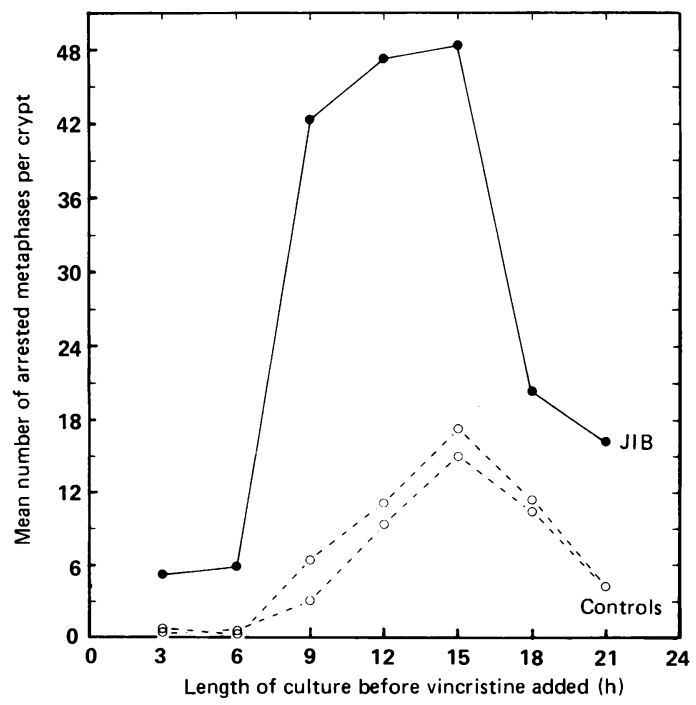

Fig. 1 Pilot experiment to determine optimum length of culture before measuring crypt cell production rate (CCPR).

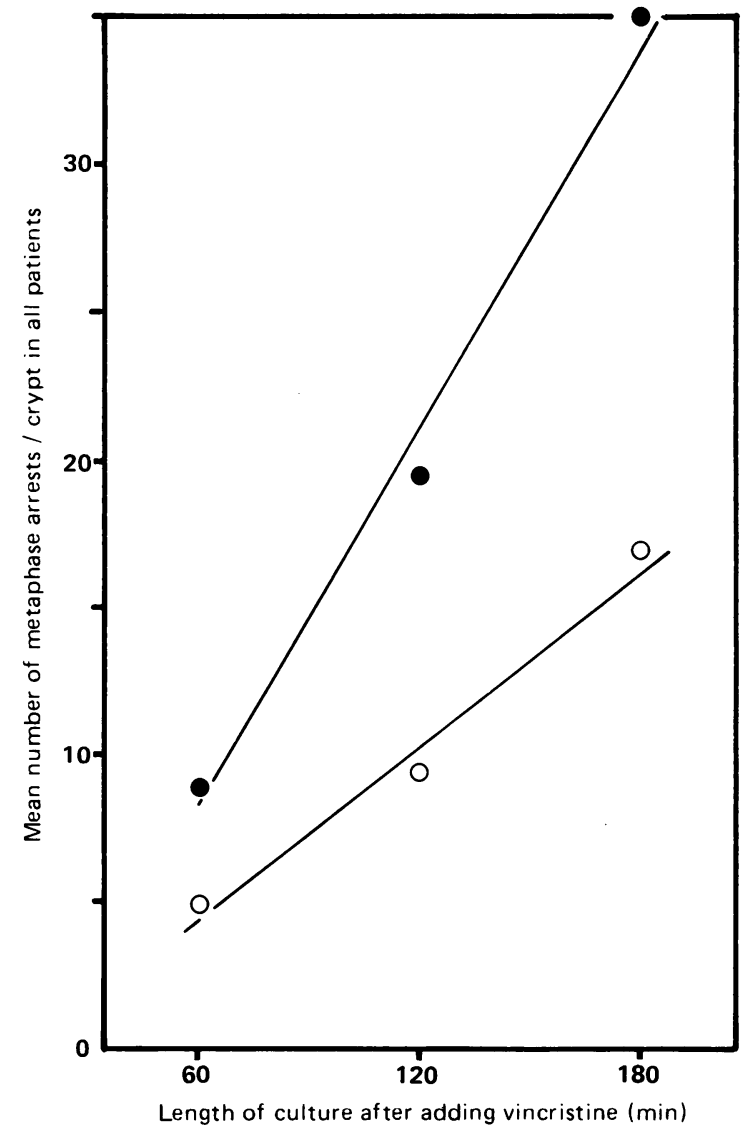

Fig. 2 Mean crypt cell production rates (CCPR) for the two groups. JIB - : controls - $\bigcirc$.

Crypt cell production rate changes of similar magnitude were seen in the colon of rats killed six months after an equivalent JIB.$^{3}$ The extent of the response in man is remarkable, because the rectum (not the colon) was sampled and adaptation is maximal immediately adjacent to the missing segment of bowel. ${ }^{7}$ Modest increments in the width and surface area of crypts did not attain statistical significance, probably because of the small numbers sampled in this part of the experiment.

The mechanism of colonic hyperplasia after JIB has not been established. The marked increase in frequency of bowel actions may reflect greater amounts of irritative bile salts reaching the colon because of the short length of small bowel remaining in continuity. Biliary (and pancreatic) secretions are trophic, ${ }^{12}$ mitogenic, ${ }^{13}$ and carcinogenic ${ }^{14}$ to colonic mucosa. Humoral stimuli are a less likely explanation. Enteroglucagon concentrations rise by $1600 \%$ after $\mathrm{JIB}^{15}$ and might contribute to the postoperative 


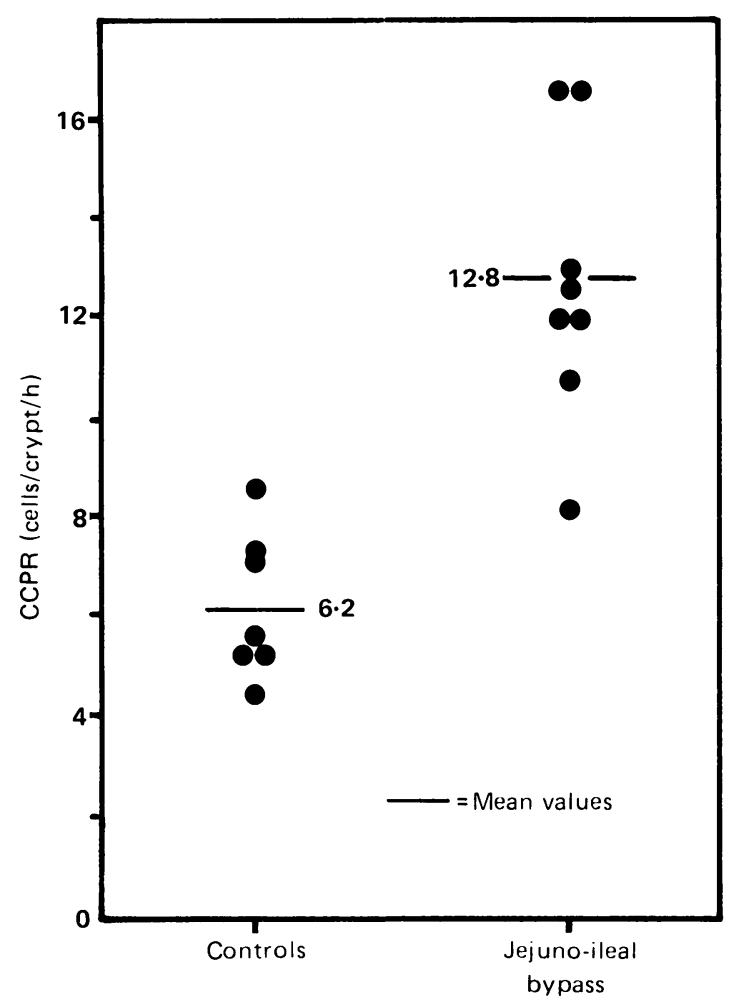

Fig. 3 Crypt cell production rates (CCPR) in seven controls and nine patients with jejunoileal bypass.

hyperplasia in the residual functioning small bowel, ${ }^{16}$ but enteroglucagon probably does not modulate colonic adaptation. ${ }^{17}$ Certainly raised concentrations of circulating enteroglucagon did nothing to overcome the inhibitory effects of colonic defunction on cell kinetics and carcinogenesis in our recent experiment. ${ }^{18}$

In experimental animals the mucosal hyperplasia that follows JIB is a potent promoter of colorectal carcinogenesis. ${ }^{3}$ Could the same hold true in man? In support, we have used organ culture to show increased CCPR in rectal biopsies of patients with active ulcerative proctocolitis, a known premalignant condition. ${ }^{19}$ Moreover these increments were more modest than those observed after JIB ( $40 \% v 105 \%)$, although they were still detectable in quiescent bowel. Against an increased risk of cancer is the profound weight reduction achieved after a successful JIB. Data from the American Cancer Society indicate that colorectal carcinoma (like many cancers) is more common in the obese and less common in those who are underweight. ${ }^{20}$ Patients with a JIB also eat less after the operation, ${ }^{21}$ and the reduction in luminal contents would be expected to cause relative colonic hypoplasia $; 2$ the type of food ingested might also change substantially. In rats a 99\% JIB causes such extreme weight loss that the cocarcinogenic effect of the operation is lost. ${ }^{4}$

In man the stimulatory effect of postoperative hyperplasia on 'spontaneous' carcinogenesis could be balanced by the inhibitory effects of weight loss and altered diet. It is reassuring to note that no evidence of colonic dysplasia could be found in a recent report of 38 patients studied at a mean of 11.5 years after JIB for morbid obesity. ${ }^{5}$ Nevertheless we believe that it is premature to discount the longterm risk of colorectal cancer, and patients with JIB should be kept under surveillance indefinitely.

We thank the South Western Regional Research Committee for generous financial support.

\section{References}

1 Payne JH, Dewind LT. Surgical treatment of obesity. Am J Surg 1969; 118: 141-7.

2 Maxwell JD, McCouran RC. Jejuno-ileal bypass: clinical and experimental aspects. Am J Clin Nutr 1977; 30: $129-47$.

3 Bristol JB, Wells M, Williamson RCN. Adaptation to jejunoileal bypass promotes experimental colorectal carcinogenesis. Br J Surg 1984; 71: 123-6.

4 Bristol JB, Davies PW, Williamson RCN. Subtotal jejunoileal bypass enhances experimental colorectal carcinogenesis unless weight reduction is profound. In: Malt RA, Williamson RCN, eds. Colonic carcinogenesis. Lancaster: MTP Press, 1982: 275-82.

5 MacFarland RJ, Gazet J-C, Pilkington TRE. A 13-year review of jejunoileal bypass. Br J Surg 1985; 72: 81-7.

6 MacFarland RJ, Talbot RW, Woolf N, Gazet J-C. Dysplasia of the colon after jejunoileal bypass. Br J Surg 1987; 74: 21-2.

7 Williamson RCN, Rainey JB. The relationship between intestinal hyperplasia and carcinogenesis. Scand $J$ Gastroenterol 1984; 19 supp 104: 57-76.

8 Challacombe DN, Wheeler EE. Growth of crypt cell nodules in duodenal mucosa during organ culture in vitro. J Clin Pathol 1985; 38: 1388-93.

9 Wright NA, Appleton DR. The metaphase arrest technique - a critical review. Cell Tissue Kinet 1980; 13: 643-63.

10 Ferguson A, Sutherland A, MacDonald TT, Allen F. Technique for microdissection and measurement in biopsies of human small intestine. J Clin Pathol 1977; 30: 1068-73.

11 Challacombe DN, McDonald DT, Wheeler EE. A quantitative assessment of jejunal villous damage in coeliac disease. Hepatogastroenterology 1983; 30: 113-5.

12 Williamson RCN, Bauer FLR, Ross JS, Watkins JB, Malt RA. Enhanced colonic carcinogenesis with azoxymethane in rats after pancreaticobiliary diversion to mid small bowel. Gastroenterology 1979; 76: 1386-92.

13 Wargovich MJ, Eng VW, Newmark HL, Bruce WR. Calcium ameliorates the toxic effect of deoxycholate on 
colonic epithelium. Carcinogenesis 1983; 4: 1205-7.

14 Rainey JB, Davies PW, Bristol JB, Williamson RCN. Adaptation and carcinogenesis in defunctioned rat colon: divergent effect of faeces and bile acids. $\mathrm{Br} J$ Cancer 1983; 48: 477-84.

15 Bloom SR, Polak JM. Enteroglucagon and the gut hormone profile of intestinal adaptation. In: Robinson JWL, Dowling RH, Rieken E-O, eds. Mechanisms of intestinal adaptation. Lancaster: MTP Press, 1982: 18999.

16 Barry RE, Barisch J, Bray GA, Sperling MA, Morin RJ, Benfield $\mathbf{J}$. Intestinal adaptation after jejunoileal bypass in man. Am J Clin Nutr 1977; 30: 32-42.

17 Savage AP, Matthews JL, Ghatei MA, Cooke T, Bloom SR. Enteroglucagon and experimental intestinal carcinogenesis in the rat. Gut 1987; 28: 33-9.
18 Bristol JB, Ghatei MA, Smith JHF, Bloom SR, Williamson RCN. Elevated plasma enteroglucagon alone fails to alter distal colonic carcinogenesis in rats. Gastroenterology 1987; 92: 617-24.

19 Allan A, Bristol JB, Williamson RCN. Crypt cell production rate in ulcerative proctocolitis: differential increments in remission and relapse. Gut 1985; 26: 9991003.

20 Lew EA, Garfinkel L. Variations in mortality by weight among 750,000 men and women. J Chronic Dis 1979; 32: 563-76.

21 Iber FL, Cooper M, Jejunoileal bypass for the treatment of massive obesity. Prevalence, morbidity and short and long-term consequences. Am J Clin Nutr 1977; 30: 4-15.

22 Williamson RCN. Disuse atrophy of the intestinal tract. Clin Nutr 1984; 3: 169-70. 